\title{
Centrally and Wide-Area Integrated Management of School Administration/Academic Affairs
}

\author{
Using a web application browser version
}

\author{
Kayo Hirakawa \\ Apsis Corporation
}

\begin{abstract}
: te@chernavi is an application for the secure management of personal information and students' records in school. It aims to support schools that are undergoing big changes brought by structural reforms of the Japanese society from the perspective of school administration, which is a key part of school management. It realizes also a secure system irrespective of platforms thanks to system development with open resources.
\end{abstract}

Keywords: te@chernavi, ASP, information security, students' personal records, open sources, JAVA.

\section{INTRODUCTION}

"te@chernavi" has been planned and developed by our company since the year 2000 . We have developed a system of $100 \%$ native web application for the transaction of academic affairs that is a key operation for schools, and we are offering it as a solution to achieve a wide-area centrally integrated management.

This centrally integrated system has already been in operation for 8 high schools that are run by Fukuoka prefecture for 4 years which is the first case in the whole of Japan.

Now we are at the next stage and conducting a new experiment in Saga prefecture. As a joint project of industry-government-academia, transaction by active server pages (ASP) of school administration of prefectural high schools is under way. A server is installed at a private company, and input/output is done with Syn-client at school. Aims of this experiment are to make clear the effectiveness of the central control as to the "personal information security" at school and to realize the "students' personal records" by a uniform management. When its effectiveness becomes clear, the education board to take advantage of the school administration by ASP 
at all public schools in Saga prefecture, and in future will most likely allocate a budget. At present, disintegrated control is done at most schools and the reality is far from the uniform management and the central control in their real meanings. We strongly hope that our vision will meet with approval and come into wide use.

\section{MODEL PROPOSED BY "TE@CHERNAVI"}

\subsection{Materialization of the Wide-Area Integrated Management by Web}

The important factors of the system are:

- Shared use of a Web server for the transaction of academic affairs by multiple schools (ASP Model)

- Use of open sources

- Integrated management of data and application by server

- The possibility of Internet connection where available

- Platform independent

- Licenses don't arise from clients' OS and tools, as the building is with open sources.

- The maintenance is done on the server by remote control.

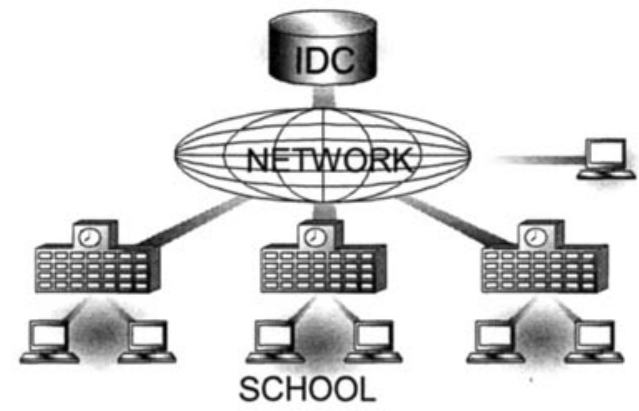

\section{WIDE-AREA CENTRALIZED MANAGEMENT MODEL OF LOCAL GOVERNMENT}

We have put into practice the first model of the centralized management in Fukuoka prefecture. Eight prefectural high schools of each different curriculum are managed with a server installed in a computer room at one of these high schools. Teachers at these schools start up a Web browser with a client on their individual desks to get access to the server directly and input scholastic performances, attendance, etc., or output ledger sheets.

The backbone of the network, "Fukuoka Gigabit Highway", is provided by Fukuoka Prefecture. 
These autonomous networks use VPN (Virtual Private Network) for security.

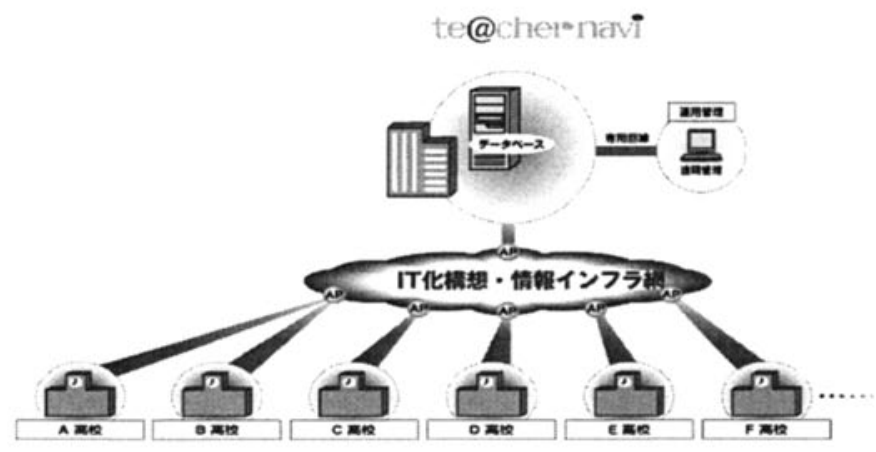

Features of this system are:

- There are no systems, no tools, no data at clients.

- Usable when the browser runs.

- Doesn't depend on the client's PC.

\section{SYSTEM ARCHITECTURE}

Features of the system architecture are:

- System construction of te@chernavi is done with open sources.

- OS is constructed with UNIX, Pure JAVA and it operates regardless of platform.

- Communication is done with the TCP/IP protocol.

- The environment includes any machine operating a Web browser.

- JAVA script is used for comfortable operation on the screen.

- Fine output of ledger sheets is through PDF.

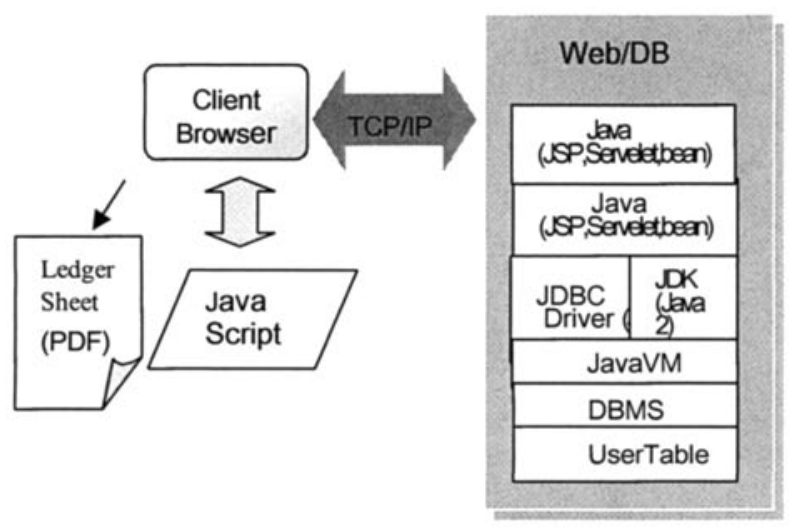




\section{5. “ACT FOR PROTECTION OF COMPUTER PROCESSED PERSONAL DATA" AND PERSONAL DATA SECURITY AT SCHOOL}

In Japan, the Personal Information Protection Law was enacted in 2005. Even for the personal information security at school, countermeasures that are much stricter than ever before are now required. Schools are under constant threat of attack.

Meanwhile, they can be called treasure- houses of personal information. Then, what kinds of countermeasures should be taken ? What are posing major threats to schools?

- Physical intrusion into the information system

- Illegal access from the outside(steppingstone, spoofing)

- Unauthorized access from the inside

- Computer virus infection

- Convulsion of nature(fire, damage by wind and flood, earthquake, thunderbolt)

The school is a treasure house of private information. Information on individual's privacy includes fields such as:

Address, Name, Telephone No., Parents' names, ..... Academic record, Record of attendance, Special activities, Guidance record, ......

Info on wishes as to the future course, Info on the future course ......

Address, Name, Age, Family makeup ..... Career history, Health check-up ..

Distributed Management at School Site involves:

- Final output/storing is in the form of "paper."

- Preparation process is with the "digital data."

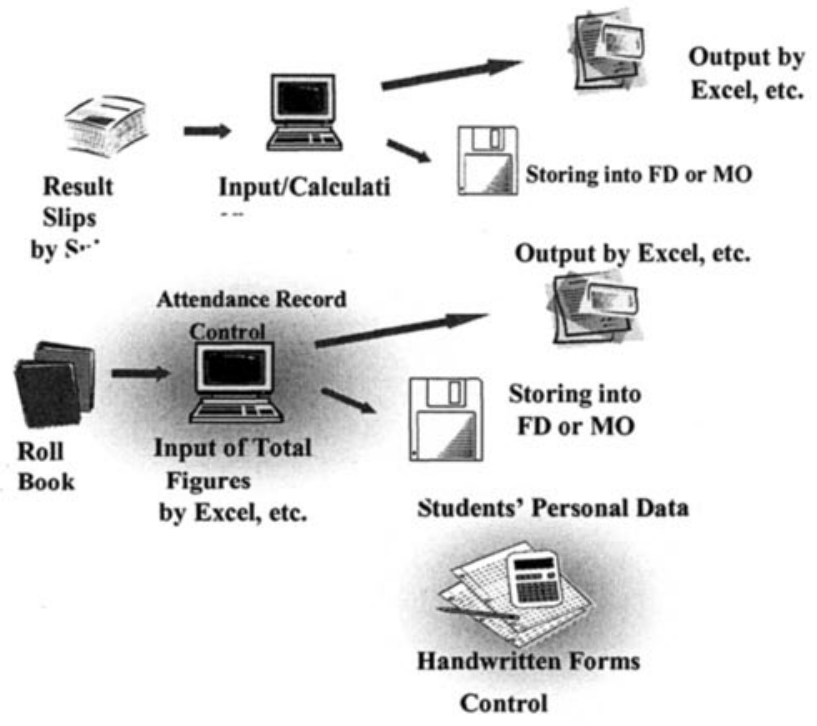




\section{CONVENTIONAL ISSUES OF SYSTEM OPERATION AT SCHOOL}

The situation in schools is characterised by:

- There are many handmade programs (Excel, Access, etc.)

- Each school has established its own system.

- There are transfers of teachers who are involved in the system operation and maintenance.

- A system and network controller is needed for each school.

- The required skill level is going up for the system controller.

- The backup work is complicated.

- The management/operation cost continues to increase.

- There is a risk of information leakage.

- The data dispersion makes it difficult to get the up-to-the-minute information.

- There is concern over possible inconsistency of data.

- Information is shared within narrow limits.

Available machines are limited.

\section{7. “TE@CHERNAVI”SOLUTIONS TO ISSUES}

At School, materialization is by a centrally integrated management oncampus LAN server. At Education Board, materialization is by a wide-area centrally integrated management info server. This creates a system where:

- Real-time alterations/changes have become possible thanks to the remote maintenance.

- Trouble shooting has been speeded up thanks to remote maintenance.

- Security measures have been centralized and fortified.

- Dispersed management at the side of the client has been eliminated.

- Licenses don't arise from OS and tools.

- It doesn't matter what terminal machines and OS clients have.

- It doesn't matter what printing machines they have.

- The operation screen display has been made common.

- The cost of management and operation has been lowered.

- Consistency of data is guaranteed.

\section{DEVELOPMENT OF SYSTEMS FOR SCHOOLS}

In Japan, the government implemented e-Japan Strategy with the aim of becoming an IT nation from 2000 through 2005. In the field of education, improvement of infrastructure at public high schools was promoted nationwide. From 2006 onward, the government has launched u-Japan Strategy with the aim of becoming a ubiquitous society in which connection 
to the internet and its utilization will become possible "whenever, wherever, whoever, and whatever."

Regarding the personal information security at school, there had been problems such as taking-out of information from office, loss, theft, and so forth in the era of stand-alone PC. The situation has become more serious these days because all schools have been connected to the Internet.

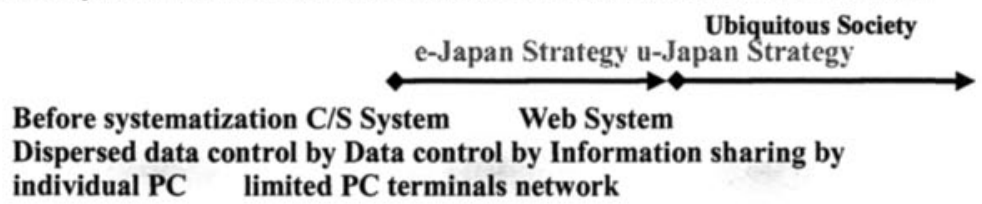

1990s First half of 2000s After 2005

Materialization of Materialization of Materialization of partial digitalization of centralized control by wide-area centralized data by school LAN control, Interactive info, Instantaneousness

From handwriting to Efficiency-up of Academic affairs have print-out academic affairs become Management time constraints

\section{MATERIALIZATION OF "INDIVIDUAL CARTE"}

"te@chernavi" has materialized the individual carte by means of a unified control of all personal information starting from entrance to school until graduation. The integrated and unified management has made it possible to look through information on each individual student, supporting teachers for meticulous guidance to their students. This sort of information can be integrated and outputted.

\subsection{An Example}

- Personal info (name, facial portrait, address, alma mater, etc)

- HR history while in school (academic year, class, ID no., home room teacher, etc)

- Attendance record while in school (absence, tardiness, leaving school early, etc.)

- School register changes (moving in, moving out, leave of absence, suspension, overseas education, etc.)

- Extracurricular activities, etc. (signing-up date, quitting date, etc.)

- Academic record history

- Health record (health data, utilization of the school nurse's office, etc.)

- Guidance history

- Qualification obtained

- Course desired 


\section{SYSTEM CORRESPONDING TO JABEE}

As one of its applications, we can refer to JABEE, that is, the Accreditation System for Engineering Education in Japan. JABEE demands standardization of criteria for the scholastic achievement assessment, credit earning and also disclosure of information. To this end, all elements such as attendance hours and academic results are to be translated into numerical points and its process needs to be verifiable rationally and objectively. te@chernavi is the system that meets these demands.

- Every-hour input of attendance (attendance/absence, results, tardy, reasons for early leaving, etc)

- Academic result data (raw scores, item scores, evaluation scores, ratings, etc)

- Grip on the process

JABEE demands preservation of the examination papers and various kinds of materials. "te@chernavi" can output all forms in PDF.

\section{THE POSSIBILITY OF AN ACADEMIC AFFAIRS TRANSACTION SYSTEM WHICH ENABLES INTERACTIVITY AND INSTANTANEOUSNESS BY USING THE WEB}

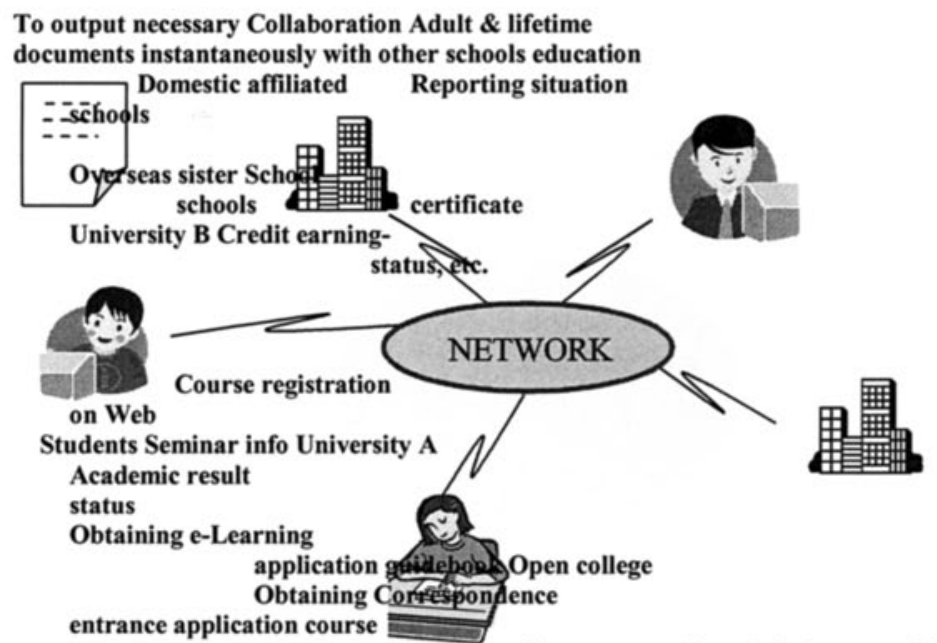

$$
\begin{gathered}
\text { form } \\
\text { Applicants for entrance }
\end{gathered}
$$

Finally, I would like to introduce a future image envisioned by te@chernavi. Thanks to the network that links school and students, a form of study irrespective of time and space will be realized. te@chernavi will provide a key administration processing service for the academic result control, accreditation, issuance of certificates, and so forth with its own 
school administration data-base. We believe that we should aim at realization of a meticulous education for each individual student by means of the information network. It is impossible for the conventional processing system of the academic affairs that was built in the age of uniform education to evolve into the system which manages each individual's data irrespective of time and space.

In this sense, our "te@chernavi" can be a solution and will contribute to the changes of schools. As a measure to counter violation of security such as hacking, setting up a transaction database is being considered separately from the main database.

\section{CONCLUSION}

Schools in Japan are currently at a big turning point. The dwindling number of children is forcing all schools to alter what a school should be. The centralized, uniformed and cram education method which has been consistently applied ever since the Meiji era after World War II is now under reassessment, and individualization and decentralization have become key words.

The advancement of computerization is expected to make a great contribution to this time for a change. Communication infrastructure at schools has been prepared under the government policy of the e-JAPAN Strategy (2000-2005.)

Since 2005, the u-Japan Strategy, realization of the Ubiquitous Society, has been hammered out, aiming at a society where people can hook up to the net and use it "Whenever, Wherever, Whoever, and Whatever."

I believe that we should aim at realization of a meticulous education for each individual student by means of the information network. The conventional processing system for the academic affairs that has been built in the age of the uniform education can be regarded as impossible to materialize the system that manages each individual's data regardless of the time and the place. In this sense, our "te@chernavi" can be a solution that will contribute to school change. 